Check for updates

Cite this: RSC Adv., 2017, 7, 41945

Received 5th July 2017

Accepted 17th August 2017

DOI: $10.1039 / c 7 r a 07417 d$

rsc.li/rsc-advances

\section{Co-Fe hydrotalcites for efficient removal of dye pollutants via synergistic adsorption and degradation}

\begin{abstract}
Feifei Chen, (D) *ab Xi Wu, ${ }^{\mathrm{a}}$ Ran $\mathrm{Bu}^{\mathrm{a}}$ and Feng Yang ${ }^{\mathrm{a}}$
Layered double hydroxides (LDHs) with hydrotalcite-like structures containing Co(I) and Fe(II) were prepared and used for the removal of direct red 23 (DR23) from water solution. These CoFe-LDHs were characterized before and after reaction by XRD, FTIR, BET, and XPS. The factors affecting the adsorption and catalytic performance of the CoFe-LDHs were systematically investigated. The adsorption process followed pseudo-first-order kinetics, while equilibrium adsorption isotherm data were well fitted by the Freundlich model. Moreover, CoFe-LDHs exhibited high catalytic activity in the degradation of direct red 23 in the $\mathrm{pH}$ range 4-10. Under a catalyst dosage of $0.5 \mathrm{~g} \mathrm{~L}^{-1}$ and $\mathrm{H}_{2} \mathrm{O}_{2}$ concentration of $6.5 \mathrm{mmol} \mathrm{L}^{-1}$, the degradation ratio of direct red 23 was $95.6 \%$ after 30 min. The adsorption-degradation relationship in the presence of CoFe-LDHs was investigated. Intermediates were detected by GC/MS and a possible pathway for DR23 degradation was proposed. The reaction mechanism showed that cobalt ions play a critical role in the catalytic performance of CoFe-LDHs. Furthermore, the catalytic activity of CoFeLDHs was maintained after three reaction cycles, demonstrating the recyclability and stability of this catalyst.
\end{abstract}

\section{Introduction}

Dye wastewater is among the most polluted types of wastewater due to its high chemical oxygen demand (COD), strong color, high $\mathrm{pH}$, and low biodegradability. During the dyeing process, $10-15 \%$ of the utilized dyes are discharged into the environment. These effluents can have serious effects on the environment and public health when disposed of improperly. Moreover, different types of dyes with various chemical structures are used in dyeing and finishing plants, which complicates the treatment of textile wastewaters. Azo dyes, characterized by one or more azo groups $(-\mathrm{N}=\mathrm{N}-)$, constitute over $50 \%$ of all textile dyes and have been widely used in the printing and dyeing industries. Several methods have been applied to removing dyes from wastewater, such as adsorption, coagulation, flocculation, and membrane treatment. ${ }^{\mathbf{1 - 4}}$ However, conventional chemical and biological methods are not efficient means of degrading azo dyes, only transferring the dyes from the liquid phase to the solid phase or another liquid phase, which can cause secondary pollution. Biological treatments are regarded as environmentally friendly methods. However, azo dye wastewaters with $\mathrm{BOD}_{5} / \mathrm{COD}$ ratios of less

${ }^{a}$ College of Chemistry and Chemical Engineering, Wuhan Textile University, Wuhan, 430073, Hubei, China. E-mail: chff1977@163.com; Fax: +86-27-59367336; Tel: +8627-59367336

${ }^{b}$ Hubei Key Laboratory of Biomass Fibers and Eco-dyeing and Finishing, Wuhan Textile University, Wuhan, 430073, Hubei, China than 0.3 indicate low biodegradability and unsatisfactory biodegradation. ${ }^{5}$ Therefore, it is necessary to find an effective method to remove azo dyes from wastewaters.

Advance oxidation processes (AOPs) are effective for degrading dyes in water by destroying double bonds in the dyes molecules. Hydroxyl free radicals $\left({ }^{\circ} \mathrm{OH}\right)$ are generated in this process, which are the most powerful oxidizing species. These 'OH species can decompose many organic pollutants to yield short-chain organic components, $\mathrm{H}_{2} \mathrm{O}$, and $\mathrm{CO}_{2}$ as the degradation products. Fenton oxidation is a common AOP using dissolved ferrous salt as catalyst. Electron transfer between $\mathrm{Fe}^{2+}$ and $\mathrm{H}_{2} \mathrm{O}_{2}$ generates ${ }^{\circ} \mathrm{OH}$ radicals via a simple process that is low-cost and environmentally friendly. However, the common homogenous Fenton reaction has some significant disadvantages, such as requiring low $\mathrm{pH}$ values (usually $\mathrm{pH} 2-4$ ) and generating large amounts of sludge. Therefore, it is necessary to adjust the $\mathrm{pH}$ before and after this reaction process to deal with the iron sludge. ${ }^{6,7}$

To overcome these drawbacks, various heterogeneous Fenton catalysts have been proposed. Active carbon, biosorbents, clay, alumina, and silica have been used as efficient supports for iron and iron oxides. ${ }^{8}$ Use of these supports enhances the dispersion of iron-containing active sites, but produces marked iron leaching. Other researchers have focused on heterogeneous Fenton catalysts containing ferrous and ferric ions, such as goethite, hematite, ferrihydrite, and pyrite. ${ }^{9}$ Furthermore, $\mathrm{Co}^{2+}$ and related cobalt salts can be used to degrade pollutants in the presence of $\mathrm{H}_{2} \mathrm{O}_{2}$ as an oxidant. ${ }^{10}$ 
Hydrotalcites are an important class of lamellar anionic clay with the general formula $\left[\mathrm{M}_{1-x}^{\mathrm{II}} \mathrm{M}_{x}^{\mathrm{III}}(\mathrm{OH})_{2}\right]^{x+}\left[\mathrm{A}^{n-}\right]_{x / n} \cdot m \mathrm{H}_{2} \mathrm{O}$ $\left(\mathrm{M}^{\mathrm{II}}=\mathrm{Mg}, \mathrm{Zn}, \mathrm{Ni}\right.$, etc. $\mathrm{M}^{\mathrm{III}}=\mathrm{Al}, \mathrm{Cr}$, etc. $)$, in which $\mathrm{M}^{\mathrm{III}}$ can partially substitute for $\mathrm{M}^{\mathrm{II}}$ and the positive charge is balanced by anions (carbonate, sulfate, nitrate, etc.) arranged in the interlayer. Due to the exchangeability of interlayer anions and high charge density of the laminate, hydrotalcites have attracted great interest for removing various anions. Currently, layered double hydroxides (LDHs) and modified LDHs have been employed in processes to remove pollutants from aqueous solution, including fluoride, heavy metals, humic acid, and dyes. ${ }^{11-13}$ LDHs have also been shown to act as heterogeneous Fenton catalysts to degrade organic pollutants. ${ }^{14,15}$

Oxidative degradations primarily occur on the surface of a heterogeneous catalyst. Therefore, adsorption on the catalyst surface plays a key role in the degradation process. ${ }^{16}$ Previous research has demonstrated that an increase in the affinity of the organic pollutant for the catalyst can accelerate degradation. In this work, Co-Fe LDHs (CoFe-LDHs) are synthesized and used as heterogeneous Fenton catalysts for the degradation of direct red 23 (DR23), a typical azo dye often used as a model pollutant. The features of DR23 adsorption and degradation on CoFeLDHs were investigated under various experimental conditions. The results show that the combination of $\mathrm{Co}^{2+}$ and $\mathrm{Fe}^{3+}$ has the strongest acceleration effect on the Fenton reaction. Moreover, CoFe-LDHs have very low solubility in water and metal ions that show reduced leaching. Furthermore, the reaction mechanism for $\mathrm{H}_{2} \mathrm{O}_{2}$ activation on the catalyst surface is discussed.

\section{Experimental}

\subsection{Materials}

DR23 was purchased from Jiangsu Shenxin Dyestuff Chemicals Co., Ltd and used without further purification. DR23 solution was prepared by dissolving DR23 in double distilled water. $\mathrm{FeCl}_{3} \cdot 6 \mathrm{H}_{2} \mathrm{O}, \mathrm{CoCl}_{2} \cdot 6 \mathrm{H}_{2} \mathrm{O}, \mathrm{H}_{2} \mathrm{O}_{2}$ (30 wt $\%$ ), $\mathrm{NaOH}$, and $\mathrm{Na}_{2} \mathrm{CO}_{3}$ were of analytical grade and obtained from Sinopharm Chemical Reagent Co., Ltd.

\subsection{Synthesis and characterization of CoFe-LDHs}

CoFe-LDHs with a Co/Fe molar ratio of 2 were prepared using the coprecipitation method. In this method, a mixture of $\mathrm{FeCl}_{3} \cdot 6 \mathrm{H}_{2} \mathrm{O}$ and $\mathrm{CoCl}_{2} \cdot 6 \mathrm{H}_{2} \mathrm{O}$ solutions (total metal ion concentration, $0.46 \mathrm{M}$ ) was combined with a precipitating solution containing $0.8 \mathrm{M} \mathrm{NaOH}$ and $\mathrm{Na}_{2} \mathrm{CO}_{3}$ in deionized water with vigorous stirring. During mixing, the $\mathrm{pH}$ was kept at around 9.0. After complete addition, the suspension was aged at $65{ }^{\circ} \mathrm{C}$ for $24 \mathrm{~h}$. The preparation was carried out under a nitrogen atmosphere. The suspension was filtered, washed with a large amount of deionized water, and dried in a vacuum oven.

X-ray diffraction (XRD) patterns were measured on Bruker D8 Advance X-ray diffractometer ( $\mathrm{Cu} \mathrm{K} \alpha$ source, $\lambda=0.154 \mathrm{~nm}$ ) in the $2 \theta$ range of $5-80^{\circ}$. Fourier transform infrared (FT-IR) spectra were analyzed on a Bruker spectrometer in the region $400-4000 \mathrm{~cm}^{-1}$. Chemical compositions of the CoFe-LDHs were determined by inductively coupled plasma atomic emission spectroscopy (ICP-AES) (ICP2060T, Skyray Instrument Inc.). Specific surface areas were analyzed using the BET method. $\mathrm{N}_{2}$ adsorption-desorption was performed on a micromeritics TristarII3020 instrument at 77 K. X-ray photoelectron (XPS) spectra were recorded on ESCALAB 250Xi X-ray photoelectron spectroscope with monochromatic Al $\mathrm{K} \alpha(1486.6 \mathrm{eV})$. The binding energies were calibrated with respect to $\mathrm{C} 1 \mathrm{~s}(284.6 \mathrm{eV})$. The zeta potentials of adsorbents were measured using a Zetasizer Nano ZS90 instrument at pH values of 4-11.

\subsection{Adsorption and catalytic degradation}

Typical adsorption experiments were performed with catalyst $(0.1 \mathrm{~g})$ in DR23 solution $\left(100 \mathrm{~mL}, 150 \mathrm{mg} \mathrm{L}^{-1}\right)$. This suspension was mechanically stirred to establish an adsorption equilibrium. After reaching equilibrium, the suspension was filtered through a $0.45 \mu \mathrm{m}$ PES filter. Dye concentrations in the filtrate were measured using UV-visible spectrophotometry at the maximum adsorption wavelength $(\lambda=506 \mathrm{~nm})$. Investigation of the adsorption process kinetics was performed at $25{ }^{\circ} \mathrm{C}$. Suspensions were stirred for different times (5-600 $\mathrm{min})$. To study the sorption isotherms, the adsorbents $\left(50 \mathrm{mg} \mathrm{L}^{-1}\right)$ and dye solutions at different concentrations $\left(10-200 \mathrm{mg} \mathrm{L}^{-1}\right)$ were stirred at equilibrium at $25^{\circ} \mathrm{C}$.

The catalytic activities of the CoFe-LDHs were evaluated using DR23 degradation in the presence of a certain amount of $\mathrm{H}_{2} \mathrm{O}_{2}$. The $\mathrm{pH}$ was adjusted using $0.1 \mathrm{M} \mathrm{HCl}$ and $\mathrm{NaOH}$ solutions. At regular time intervals, the suspension was filtered through a $0.45 \mu \mathrm{m}$ PES filter to completely remove catalyst particles. In each recyclability test, the catalyst was filtered, washed thoroughly with deionized water, and dried at $50{ }^{\circ} \mathrm{C}$. The dye concentration in the solution was measured by UV-visible spectrophotometry (METASH, V-5600) at the maximum adsorption wavelength of the dye. Total organic carbon (TOC) was measured using a Vario TOC Elementar analyzer. TOC was calculated from the difference between total carbon and total inorganic carbon. Electron paramagnetic resonance (EPR) spectra were collected using a Bruker A300 spectrometer. The nitrone spin trap, 5,5-dimethyl-1-pyrroline $N$-oxide (DMPO), was used to detect free radicals. Intermediate products of DR23 were analyzed by $\mathrm{GC} / \mathrm{MS}$. The GC column was operated at $80^{\circ} \mathrm{C}$ for $2 \mathrm{~min}$ and then increased to $250{ }^{\circ} \mathrm{C}$ at a rate of $15{ }^{\circ} \mathrm{C} \mathrm{min}^{-1}$.

\section{Results and discussion}

\subsection{Characterization of CoFe-LDHs}

XRD analysis of CoFe-LDHs before and after the Fenton reaction was performed to identify the phase structure (Fig. 1(a)). In the XRD patterns of the CoFe-LDHs, diffraction signals located at $11.6^{\circ}, 23.2^{\circ}, 34.0^{\circ}, 38.7^{\circ}, 59.1^{\circ}$, and $60.5^{\circ}$ were characteristic of CoFe-LDHs (PDF 50-0235). These peaks corresponded to the (003), (006), (009), (015), (110), and (113) planes of typical hydrotalcite structures. The unit cell parameters of CoFe-LDHs $a$ and $c$ were calculated using the equations ( $a=2 d 110, c=$ $3 d 003)$. Lattice parameters $a$ and $c$ were $0.3124 \mathrm{~nm}$ and $2.3588 \mathrm{~nm}$, respectively. A similar result was observed in previous research. ${ }^{17}$ Moreover, sharp and symmetric diffraction 

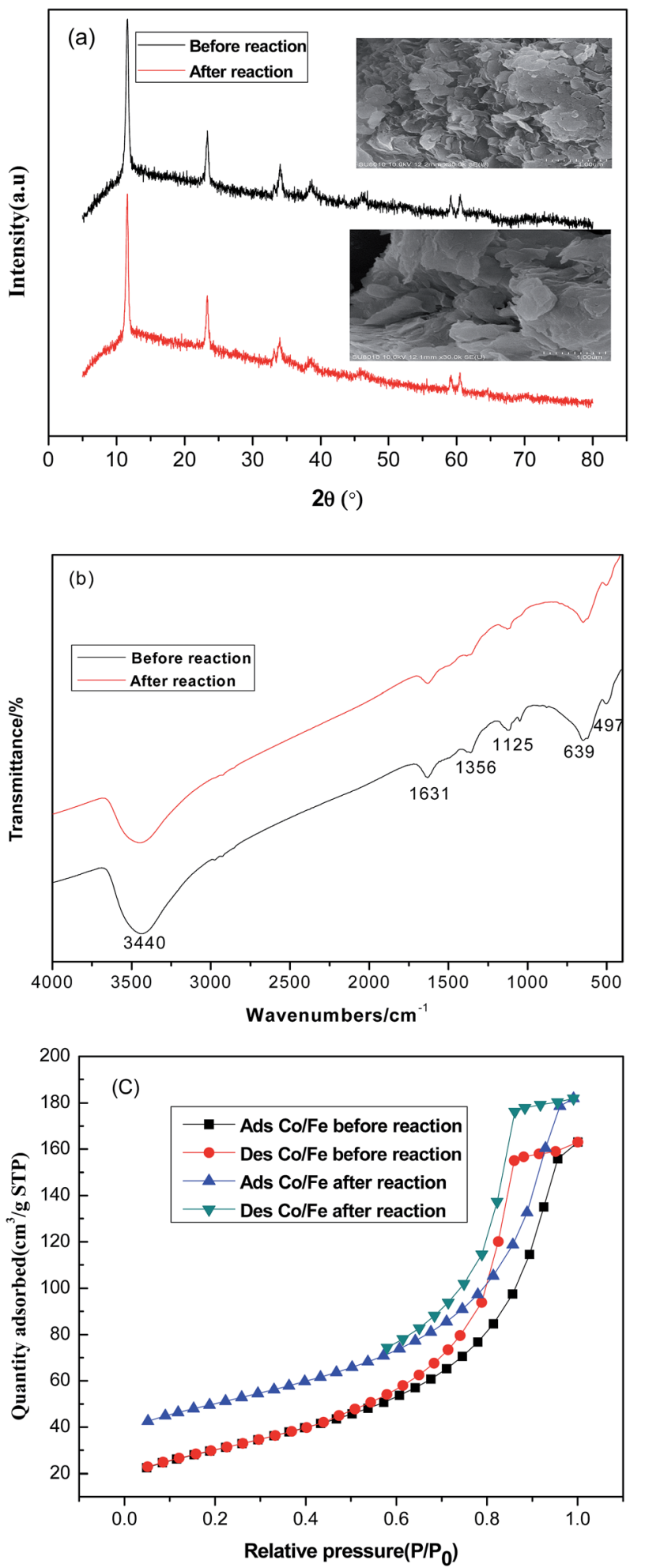

Fig. 1 Characterization of CoFe-LDHs by (a) XRD, (b) FTIR, and (c) BET $\mathrm{N}_{2}$ adsorption-desorption before and after the Fenton reaction.

peaks at low values of $2 \theta$ angles showed that the hydrotalcite phase was highly formed and that the samples were well crystallized. The SEM image (Fig. 1(a)) of the prepared CoFe-LDHs showed a plate-like morphology, containing plates several nanometers thick with a lateral distance of approximately 5-10 $\mu \mathrm{m}$.
Moreover, SEM images of the CoFe-LDHs after the Fenton reaction showed that the lamellar structure was retained.

FTIR spectra of CoFe-LDHs before and after the Fenton reaction are shown in Fig. 1(b). The adsorption band at around $3440 \mathrm{~cm}^{-1}$ was attributed to the stretching vibration of $-\mathrm{OH}$ in the layer hydroxyl groups and interlayer water molecules. The medium intensity band at $1631 \mathrm{~cm}^{-1}$ was attributed to the bonding mode of interlayer water molecules. ${ }^{18}$ The band at $1356 \mathrm{~cm}^{-1}$ was assigned to the antisymmetric stretching vibration of carbonate species. ${ }^{19}$ The peak at $1125 \mathrm{~cm}^{-1}$ was attributed to the $\mathrm{NO}_{3}{ }^{-}$ stretching vibration in the CoFe-LDH layers. ${ }^{20}$ Bands in the region $500-700 \mathrm{~cm}^{-1}$ were attributed to metal-oxygen-metal stretching. ${ }^{21}$

The CoFe-LDHs had a BET surface area of $108 \mathrm{~m}^{2} \mathrm{~g}^{-1}$ both before and after the reaction (Table 1). Furthermore, the pore volume showed little change during Fenton reaction, suggesting that the CoFe-LDH framework remained intact after Fenton reaction process. Both isotherms of the CoFe-LDHs were type IV (Fig. 1(c)), which indicated that CoFe-LDHs contained a mixture of micropores and mesopores. ${ }^{22}$ Hysteresis loops were of type $\mathrm{H}_{1}$ and attributed to narrow pore size distributions and well-defined structures. ${ }^{23}$

These results showed that CoFe-LDHs before and after the Fenton reaction were almost the same, suggesting that there was no detectable change in their physicochemical properties during Fenton reaction.

To investigate the surface elemental composition and valence states of CoFe-LDHs, X-ray photoelectron spectroscopy (XPS) was conducted. Fig. 2(a) shows peaks from the XPS survey spectra, which were mainly attributed to C 1 s, O 1s, Co 2p, and Fe 2p regions. ${ }^{24}$ Furthermore, Co/Fe ratios were almost constant before and after the Fenton reaction. Fig. 2(b) shows high-resolution Co $2 p$ XPS spectra before and after the Fenton reaction. The Co $2 p$ spectrum before the reaction shows two prominent peaks corresponding to Co $2 \mathrm{p}_{3 / 2}$ and Co $2 \mathrm{p}_{1 / 2}$ observed at 780.9 and $796.8 \mathrm{eV}$, respectively, along with satellite peaks. This suggested that the surface of the CoFe-LDHs was composed of $\mathrm{Co}^{2+}$. This result match reported data for $\mathrm{Co}(\mathrm{OH})_{2} \cdot{ }^{24,25} \mathrm{After}$ the reaction, the Co $2 \mathrm{p}_{3 / 2}$ peak shifted to a lower binding energy region $(779.8 \mathrm{eV})$, indicating a partial valence state transformation from $\mathrm{Co}^{2+}$ to $^{\mathrm{Co}^{3+}, 25}$ which indicated that the activities of the cobalt ions were related. No obvious change was observed in the high-resolution XPS spectra of Fe 2p before and after the Fenton reaction (Fig. 2(c)). The appearance of satellite bands near the Fe $2 \mathrm{p}$ main peaks indicated the presence of the $\mathrm{Fe}^{3+}$ valence state. Moreover, Fig. 2(d) shows the bonding energies of $\mathrm{Fe} 2 \mathrm{p}_{3 / 2}$ and $\mathrm{Fe} 2 \mathrm{p}_{1 / 2}$ of $709.2 \mathrm{eV}$ and $711.6 \mathrm{eV}$, which were ascribed to $\mathrm{Fe}^{2+}$ and $\mathrm{Fe}^{3+}$,

Table 1 BET surface and porosity characteristics of CoFe-LDHs

\begin{tabular}{llll}
\hline Catalyst & $\begin{array}{l}\text { BET surface } \\
\text { area }\left(\mathrm{m}^{2} \mathrm{~g}^{-1}\right)\end{array}$ & $\begin{array}{l}\text { Pore volume } \\
\left(\mathrm{cm}^{3} \mathrm{~g}^{-1}\right)\end{array}$ & $\begin{array}{l}\text { Pore diameter } \\
(\mathrm{nm})\end{array}$ \\
\hline $\begin{array}{l}\text { CoFe-LDHs } \\
\text { (before reaction) }\end{array}$ & 108.9 & 0.244 & 7.45 \\
$\begin{array}{l}\text { CoFe-LDHs } \\
\text { (after reaction) }\end{array}$ & 108.7 & 0.223 & 9.62
\end{tabular}



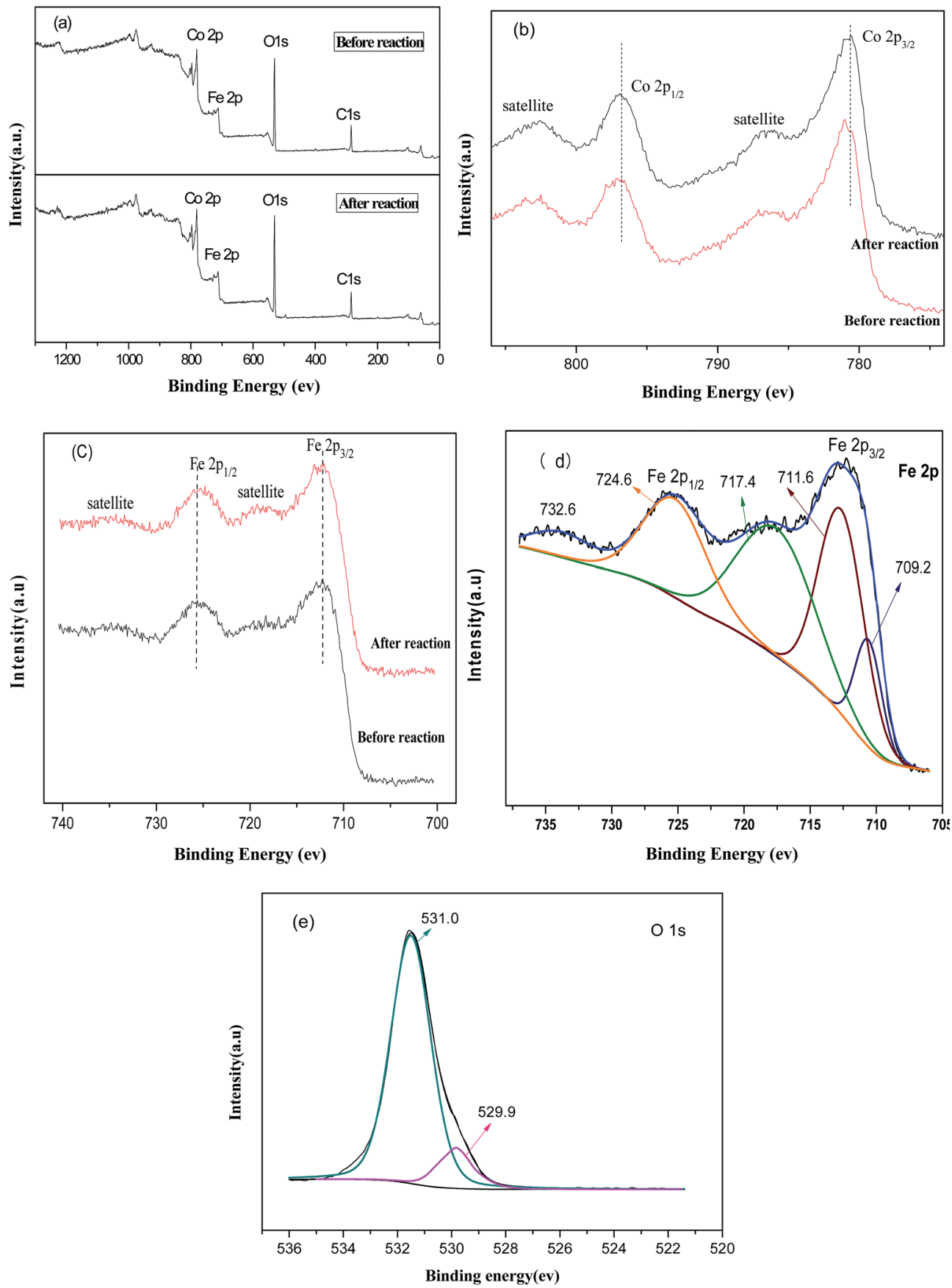

Fig. 2 (a) Full XPS spectra of CoFe-LDHs before and after the Fenton reaction, high resolution spectra of (b) Co 2p and (c) Fe 2p, (d) XPS of Fe peaks, and (e) XPS of $O$ peaks.

respectively. ${ }^{26}$ This revealed the coexistence of $\mathrm{Fe}^{2+}$ and $\mathrm{Fe}^{3+}$ at the CoFe-LDH surface. The electron couples of $\mathrm{Fe}^{3+} / \mathrm{Fe}^{2+}$ and $\mathrm{Co}^{3+} /$ $\mathrm{Co}^{2+}$ coexisted in the CoFe-LDH structure, providing notable catalytic activity. In the $\mathrm{O}$ 1s spectrum (Fig. 2(e)), the peak at $531.0 \mathrm{eV}$ was ascribed to surface hydroxyls and the peak at $529.9 \mathrm{eV}$ was attributed to bridging oxygen $\mathrm{M}(\mathrm{Co}, \mathrm{Fe})-\mathrm{O}$ linkages. ${ }^{27}$

\subsection{Decolorization of DR23}

The decolorization of DR23 in solutions at neutral $\mathrm{pH}$ was carried out under various reaction conditions, as shown in
Fig. 3(a). The results in Fig. 3(a) showed that the decolorization efficiency was almost negligible for $\mathrm{H}_{2} \mathrm{O}_{2}$ alone. This might be due to the low oxidation potential of hydrogen peroxide. ${ }^{28}$ Without $\mathrm{H}_{2} \mathrm{O}_{2}$, decolorization of DR23 with CoFe-LDHs alone was attributed to the adsorption process. DR23 decolorization reached $73 \%$ after $30 \mathrm{~min}$, which confirmed that the CoFeLDHs had a good adsorption storage capacity for DR23. When both CoFe-LDHs and $\mathrm{H}_{2} \mathrm{O}_{2}$ were present, excellent DR23 removal efficiency was obtained (up to $95.6 \%$ after $30 \mathrm{~min}$ ). It was speculated that $\mathrm{H}_{2} \mathrm{O}_{2}$ was activated by CoFe-LDHs and the Fenton reaction occurred at the surface of the CoFe-LDHs. To 

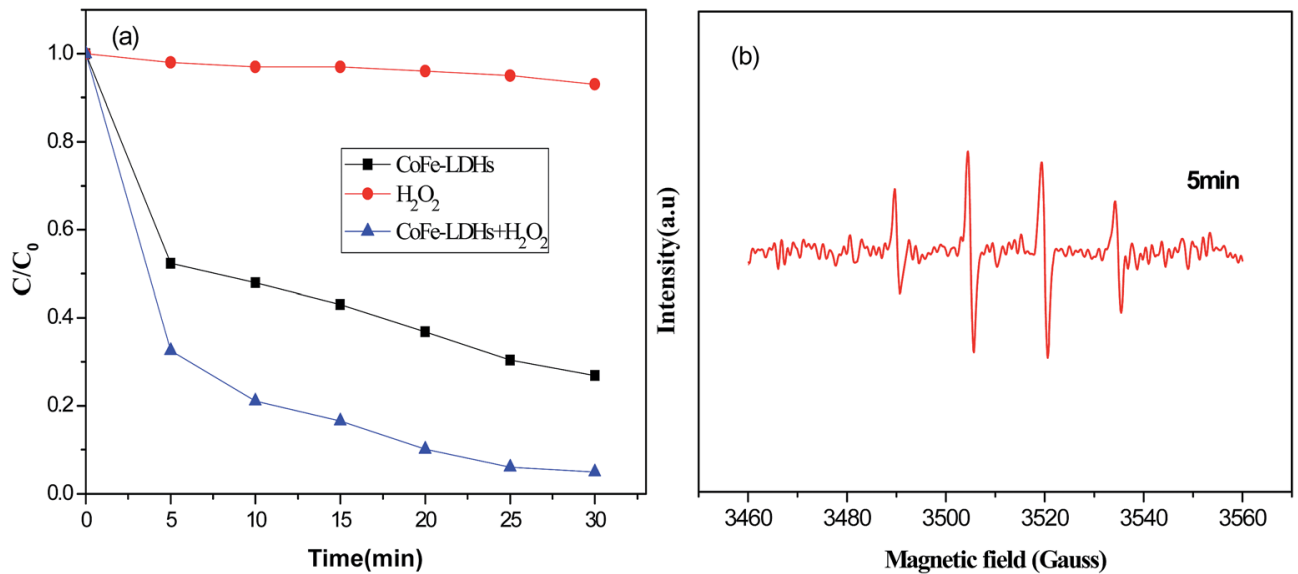

Fig. 3 (a) Decomposition of dye under different reaction conditions (reaction conditions: temperature, $25^{\circ} \mathrm{C} ; \mathrm{H}_{2} \mathrm{O}_{2}$ concentration, 6.5 mM; catalyst loading, $0.5 \mathrm{~g} \mathrm{~L}^{-1}$ ). (b) DMPO trapped electron paramagnetic resonance spectra over CoFe-LDHs.

prove this point, a DMPO-trapped EPR experiment was performed to detect ${ }^{\circ} \mathrm{OH}$ by measuring the intensity of the DMPO$\mathrm{OH}$ adduct signal (Fig. 3(b)). Quartet lines with peak height ratios of $1: 2: 2: 1$ were observed in the specific spectrum. This result confirmed that ${ }^{\circ} \mathrm{OH}$ was generated in the presence of CoFe-LDHs. ${ }^{29,30}$ These results showed that CoFe-LDHs could be used as an effective catalyst for the heterogeneous oxidation of DR23.

3.2.1 DR23 adsorption on CoFe-LDHs. Pseudo-first-order and pseudo-second-order kinetic equations were adopted to describe the adsorption process. These models can be expressed by the following equations:

Pseudo-first-order kinetic equation:

$$
\lg \left(q_{\mathrm{e}}-q_{t}\right)=\lg q_{\mathrm{e}}-\frac{K_{1}}{2.303} t
$$

Pseudo-second-order kinetic equation:

$$
\frac{t}{q_{t}}=\frac{1}{K_{2} q_{\mathrm{e}}^{2}}+\frac{1}{q_{\mathrm{e}}} t
$$

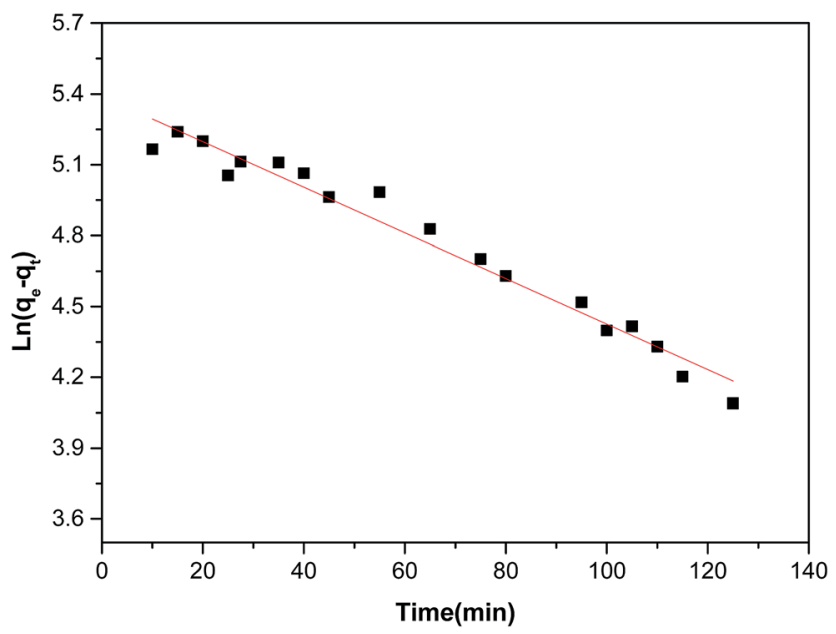

Fig. 4 Pseudo-first-order kinetics for adsorption of DR23 on CoFeLDHs. where $q_{\mathrm{e}}$ and $q_{t}$ are the equilibrium adsorption capacity and amount adsorbed in time $t$, respectively, $K_{1}\left(\mathrm{~min}^{-1}\right)$ is the pseudofirst-order equilibrium rate constant, and $K_{2}\left(\mathrm{~g} \mathrm{mg}^{-1} \mathrm{~min}^{-1}\right)$ is the pseudo-second-order rate constant.

As shown in Fig. 4 and Table 2, the high correlation coefficients (0.97) suggested that the adsorption process followed a pseudo-first-order kinetic model. Furthermore, the difference between the calculated $q_{\mathrm{e}}$ obtained from pseudo-first-order kinetic equation and the experimental $q_{\mathrm{e}}$ was small, meaning that the pseudo-first-order kinetic model was reasonable. The DR23 adsorption capacity was found to be above $200 \mathrm{mg} \mathrm{g}^{-1}$, which indicated that CoFe-LDHs are efficient materials for the adsorption of DR23 from aqueous solutions.

Equilibrium adsorption data were explored using Langmuir and Freundlich models. The Langmuir model is given by the equation:

$$
\frac{C_{\mathrm{e}}}{q_{\mathrm{e}}}=\frac{1}{q_{\max } k_{\mathrm{L}}}+\frac{C_{\mathrm{e}}}{q_{\max }}
$$

where $q_{\max }$ is the maximum adsorption capacity $\left(\mathrm{mg} \mathrm{g}^{-1}\right)$ and $k_{\mathrm{L}}$ is the adsorption intensity related to the affinity of the binding site $\left(\mathrm{L} \mathrm{mg}^{-1}\right)$.

The Freundlich model is given by the equation:

$$
\ln q_{\mathrm{e}}=\ln k_{\mathrm{F}}+\frac{\ln C_{\mathrm{e}}}{n}
$$

where $k_{\mathrm{F}}$ is the adsorption constant related to the bonding energy and $n$ is associated with the surface heterogeneity.

Table 2 Kinetic parameters of DR23 adsorption on CoFe-LDHs

\begin{tabular}{lll}
\hline Pseudo-first-order model & $q_{\mathrm{e} \mathrm{cal}}\left(\mathrm{mg} \mathrm{g}^{-1}\right)$ & 223.2 \\
& $q_{\mathrm{e} \operatorname{Exp}}\left(\mathrm{mg} \mathrm{g}^{-1}\right)$ & 210.0 \\
& $K_{1}\left(\mathrm{~min}^{-1}\right)$ & 0.01052 \\
& $R^{2}$ & 0.97 \\
Pseudo-second-order & $q_{\mathrm{e} \mathrm{cal}}\left(\mathrm{mg} \mathrm{g}^{-1}\right)$ & 45.5 \\
model & $q_{\mathrm{e} \mathrm{Exp}}\left(\mathrm{mg} \mathrm{g}^{-1}\right)$ & 210.0 \\
& $K_{2}\left(\mathrm{~g} \mathrm{mg}^{-1} \mathrm{~min}^{-1}\right)$ & $6.24 \times 10^{-4}$ \\
& $R^{2}$ & 0.79
\end{tabular}


Table 3 Parameters of Freundlich and Langmuir isotherms for adsorption of DR23 on CoFe-LDHs

\begin{tabular}{lll}
\hline Model & Parameters & \\
\hline Langmuir model & $q_{\max }\left(\mathrm{mg} \mathrm{g}^{-1}\right)$ & 173.3 \\
& $K_{\mathrm{L}}\left(\mathrm{L} \mathrm{mg}^{-1}\right)$ & $6.22 \times 10^{-3}$ \\
& $R^{2}$ & 0.62 \\
Freundlich model & $K_{\mathrm{F}}\left(\mathrm{mg}^{1 / n} \mathrm{~L}^{1 / n} \mathrm{~g}^{-1}\right)$ & 10.8 \\
& $1 / n$ & 0.1627 \\
& $R^{2}$ & 0.98
\end{tabular}

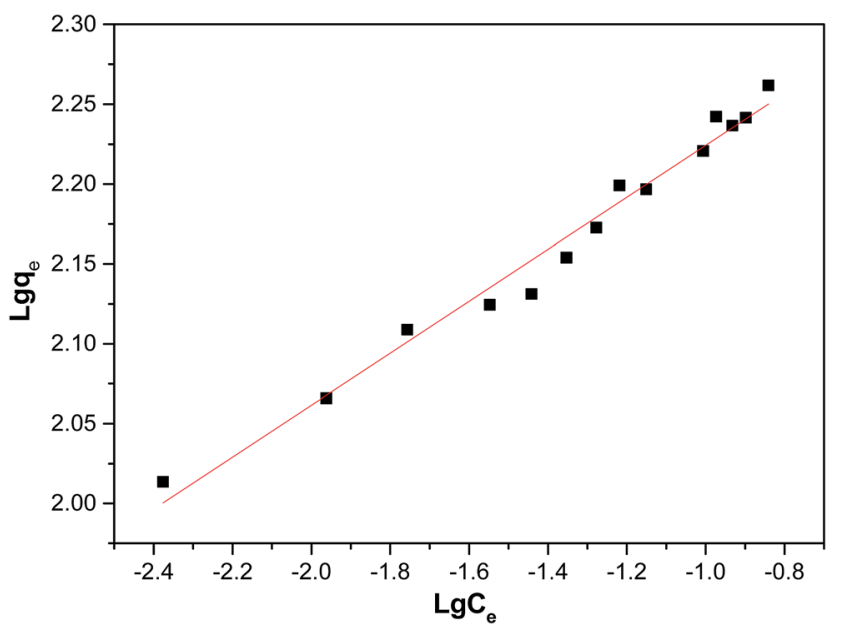

Fig. 5 Freundlich isotherm for adsorption of DR23 on CoFe-LDHs.

The isotherm parameters were calculated from the intercept and slope of the plot and are presented in Table 3. Linear plots of the Freundlich models of the DR23 adsorptions are shown in Fig. 5. According to the correlation coefficient values, the adsorption data were conformed better to the Freundlich model than the Langmuir model, perhaps due to the nonuniform distribution of active sites on the CoFe-LDH surface.

3.2.2 DR23 degradation on CoFe-LDHs. $\mathrm{H}_{2} \mathrm{O}_{2}$ played an important role in the Fenton reaction. Fig. 6(a) shows the effect of $\mathrm{H}_{2} \mathrm{O}_{2}$ concentration on DR23 degradation. DR23 degradation increased from $74 \%$ to $95 \%$ when increasing the $\mathrm{H}_{2} \mathrm{O}_{2}$ concentration from $3.2 \mathrm{mM}$ to $6.5 \mathrm{mM}$. However, further increasing the $\mathrm{H}_{2} \mathrm{O}_{2}$ concentration reduced the degradation efficiency because the degradation rate was primarily related to the concentration of $\mathrm{OH}$ generated during the reaction. The amount of ' $\mathrm{OH}$ was highly dependent on $\mathrm{H}_{2} \mathrm{O}_{2}$ concentration. The decrease in catalytic activity when the $\mathrm{H}_{2} \mathrm{O}_{2}$ concentration was too high could be attributed to the formation of ${ }^{\circ} \mathrm{HO}_{2}$ from excess $\mathrm{H}_{2} \mathrm{O}_{2}$ being used as an ${ }^{\circ} \mathrm{OH}$ scavenger, as described previously: ${ }^{31}$

$$
\cdot \mathrm{OH}+\mathrm{H}_{2} \mathrm{O}_{2} \rightarrow \cdot \mathrm{HO}_{2}+\mathrm{H}_{2} \mathrm{O}
$$

To achieve a high degradation efficiency and prevent the occurrence of radical scavengers, an $\mathrm{H}_{2} \mathrm{O}_{2}$ concentration of $6.5 \mathrm{mM}$ was adopted for further experiments.
Fig. 6(b) shows the effect of CoFe-LDH dosage on DR23 degradation under the following conditions: $\mathrm{H}_{2} \mathrm{O}_{2}$ concentration, $6.5 \mathrm{mM}$; initial dye concentration, $0.02 \mathrm{~g} \mathrm{~L}^{-1}$; neutral pH. DR23 degradation increased sharply with increasing catalyst amount from 0.1 to $0.5 \mathrm{~g} \mathrm{~L}^{-1}$. This enhanced degradation might be due to the increase in concentration of active sites of CoFe-LDHs. Further increasing the amount of CoFe-LDHs resulted in a slight increase. It was speculated that using too much CoFe-LDHs generated excessive $\mathrm{Fe}^{3+}$ irons, which might eliminate $\mathrm{H}_{2} \mathrm{O}_{2} \cdot{ }^{31,32}$

Furthermore, different types of dyes (anionic and cationic dyes) were used in the Fenton reaction. Anionic dyes (acid orange, DR23) and cationic dyes (methylene blue) were adopted in the following experiments and the results are shown in Fig. 6(c). The degradation efficiencies of acid orange and DR23 were much higher than that of methylene blue. To explain this, it is necessary to understand the surface charge on the CoFeLDHs and dyes. The surface charge of LDHs is positive due to the partial replacement of divalent metal ions with trivalent metal ions. Methylene blue with positive charges was difficult to adsorb on the surface of CoFe-LDHs because of electrostatic repulsion. Improving the degradation efficiency of cationic dyes by changing the surface properties of CoFe-LDHs should be further investigated in future.

The effect of reaction temperature on DR23 degradation was also tested, and the results are depicted in Fig. 6(d). The degradation performance of the CoFe-LDH catalyst increased with increasing reaction temperature, perhaps because the number of $\mathrm{OH}$ radicals increased at a higher temperature, leading to faster discoloration of DR23. ${ }^{33}$

DR23 mineralization, related to TOC removal from the dye aqueous solution, is shown in Fig. 7. Dye mineralization was slower than dye decolorization. For instance, DR23 decolorization was about $95.6 \%$ after $30 \mathrm{~min}$, while only $45 \%$ of DR23 was mineralized after $30 \mathrm{~min}$. This occurred because intermediate products were produced during the dye degradation process, resulting in a longer reaction time being needed. After $60 \mathrm{~min}$, TOC removal reached about $80 \%$. These results indicated that the CoFe-LDH catalyst could effectively mineralize DR23 into $\mathrm{CO}_{2}$ and $\mathrm{H}_{2} \mathrm{O}$.

3.2.3 Adsorption and degradation at different $\mathrm{pH}$ values. The effect of initial pH on DR23 adsorption and degradation was investigated. To elucidate the interaction mechanisms between DR23 and CoFe-LDHs, variations in the zeta potentials of CoFe-LDH suspensions were measured under various $\mathrm{pH}$ conditions. The experimental results are presented in Fig. 8. The zeta potential decreased with increasing $\mathrm{pH}$. This was due to particles of CoFe-LDHs capturing more negative charge. This behavior was in accordance with the effect of $\mathrm{pH}$ on the adsorption efficiency (see Fig. 8). Lower $\mathrm{pH}$ values caused the positive charge of the CoFe-LDH surface to easily attract the sulfonate group of DR23. The electrostatic interaction between the anionic dye ions $\left(-\mathrm{SO}_{3}{ }^{-}\right)$of DR23 and CoFe-LDHs might be a prominent factor affecting adsorption capacity. In general, the degradation capacity showed almost the same trend as adsorption capacity, because a higher adsorption capacity of organic pollutant on the catalyst surface facilitated a degradation reaction. However, compared with the adsorption capacity, 

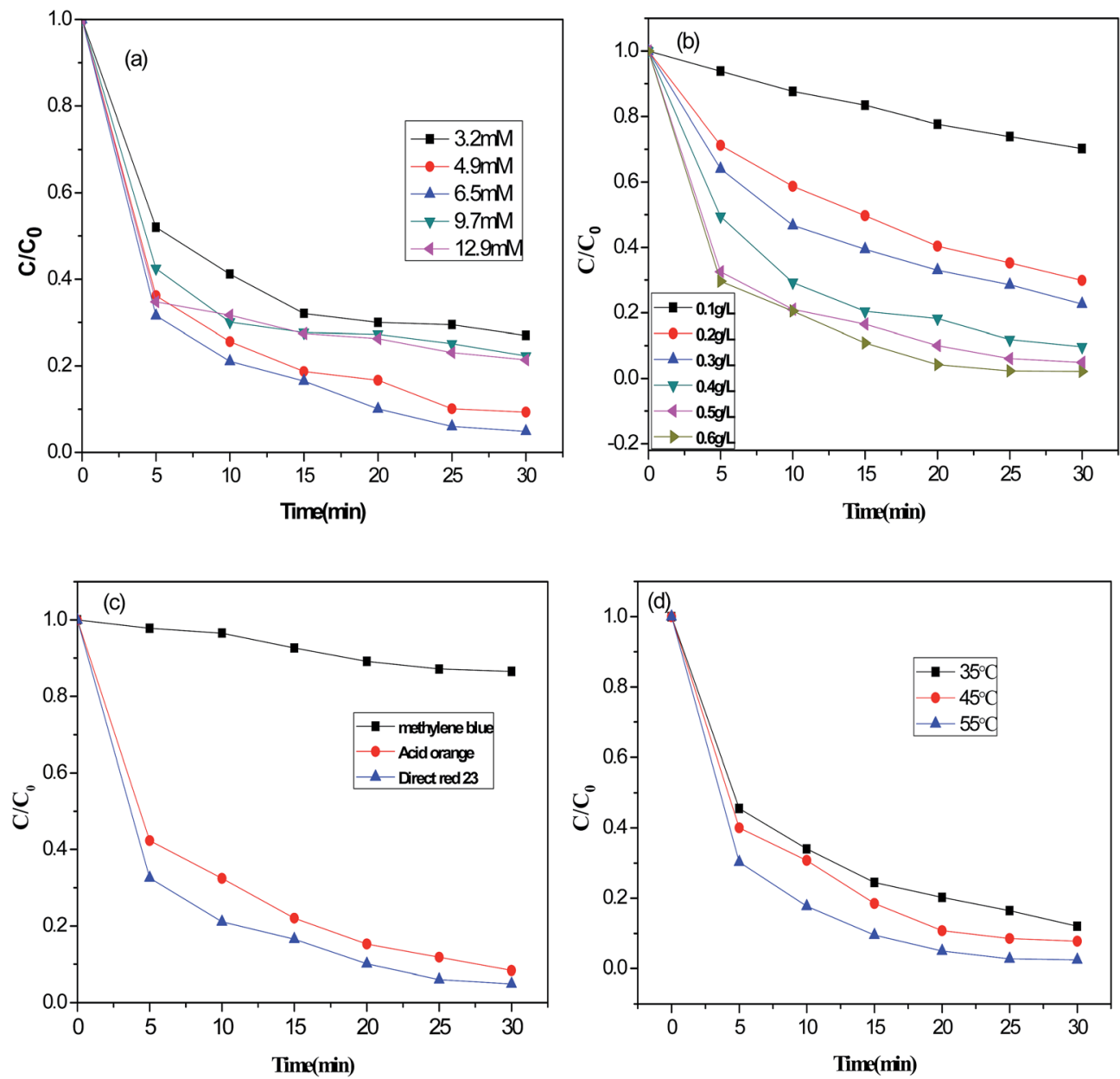

Fig. 6 Effects of experimental factors on DR23 degradation: (a) $\mathrm{H}_{2} \mathrm{O}_{2}$ concentration (reaction conditions: temperature, $25^{\circ} \mathrm{C}$; catalyst loading, $0.5 \mathrm{~g} \mathrm{~L}^{-1}$; initial dye concentration, $\left.0.02 \mathrm{~g} \mathrm{~L}^{-1}\right)$, (b) catalyst loading $\left(\mathrm{H}_{2} \mathrm{O}_{2}\right.$ concentration, $6.5 \mathrm{mM}$; initial dye concentration, $0.02 \mathrm{~g} \mathrm{~L}^{-1}$; and neutral $\mathrm{pH}$ ), (c) type of dye (temperature, $25^{\circ} \mathrm{C}$; catalyst loading, $0.5 \mathrm{~g} \mathrm{~L}^{-1} ; \mathrm{H}_{2} \mathrm{O}_{2}$ concentration, $6.5 \mathrm{mM}$; initial dye concentration, $0.02 \mathrm{~g} \mathrm{~L}{ }^{-1}$ ), and (d) temperature (catalyst loading, $0.5 \mathrm{~g} \mathrm{~L}^{-1} ; \mathrm{H}_{2} \mathrm{O}_{2}$ concentration, $6.5 \mathrm{mM}$; initial dye concentration, $0.06 \mathrm{~g} \mathrm{~L}^{-1}$ ).

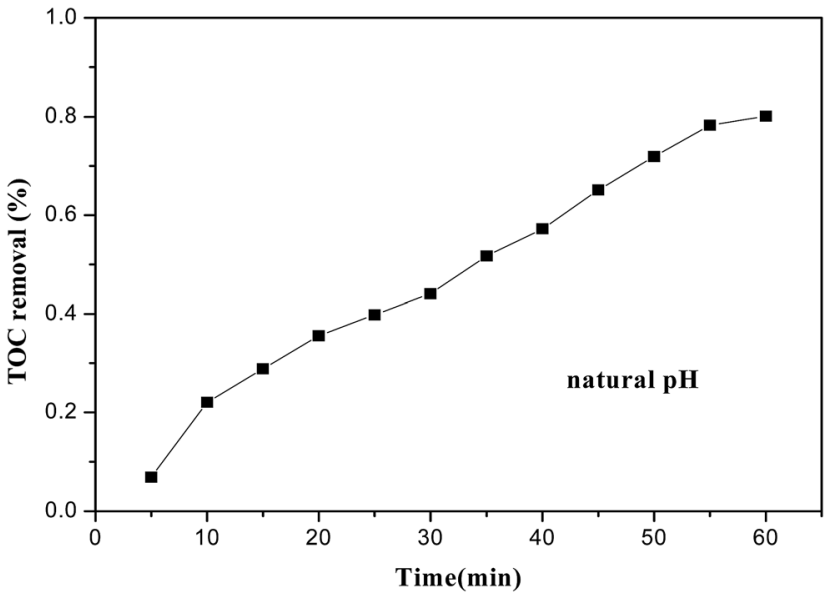

Fig. 7 TOC removal after degradation for $60 \mathrm{~min}$ (reaction conditions: temperature, $25{ }^{\circ} \mathrm{C} ; \mathrm{H}_{2} \mathrm{O}_{2}$ concentration, $6.5 \mathrm{mM}$; catalyst loading, $0.5 \mathrm{~g} \mathrm{~L}^{-1}$; initial dye concentration, $0.02 \mathrm{~g} \mathrm{~L}^{-1}$ ). the variation in DR23 degradation with changing $\mathrm{pH}$ was relatively small. DR23 degradation reached $80 \%$ within $30 \mathrm{~min}$, even at an initial $\mathrm{pH}$ value of 10 . This suggested that synergistic effects were present in this Fenton reaction. The conversion of $\equiv \mathrm{Co}^{2+} \rightarrow \equiv \mathrm{Co}^{3+}$ would be thermodynamically favorable in a basic medium $\left(E_{\mathrm{Co}(\mathrm{OH})_{3} / \mathrm{Co}(\mathrm{OH})_{2}}^{o}=0.17 \mathrm{~V}, \mathrm{pH} 14\right)$, but thermodynamically unfavorable in an acidic medium $\left(E_{\mathrm{Co}^{3+} / \mathrm{Co}^{2+}}^{o}=1.82 \mathrm{~V}, \mathrm{pH} 0\right){ }^{34}$ In contrast, LDH layers were built up by condensation of the octahedral unit, $\mathrm{OH}$ groups were shared by three octahedral cations $\left(\mathrm{Co}^{2+}\right.$ and $\left.\mathrm{Fe}^{3+}\right)$, and $\mathrm{Co}-\mathrm{OH}$ was formed in the CoFe-LDH layers. ${ }^{35}$ It could be deduced that an alkaline environment was beneficial to $\equiv \mathrm{Co}^{2+}$ / $\equiv \mathrm{Co}^{3+}$ conversion (eqn (6)). This compensated for the disadvantage in adsorption with increasing $\mathrm{pH}$ values. In brief, this showed that adsorption was beneficial for promoting Fenton reaction, but there was no linear relationship between adsorption and degradation. Furthermore, this result demonstrated that the CoFe-LDHs could be used to degrade DR23 over a wide $\mathrm{pH}$ range, making CoFe-LDHs advantageous regarding the working environment. 


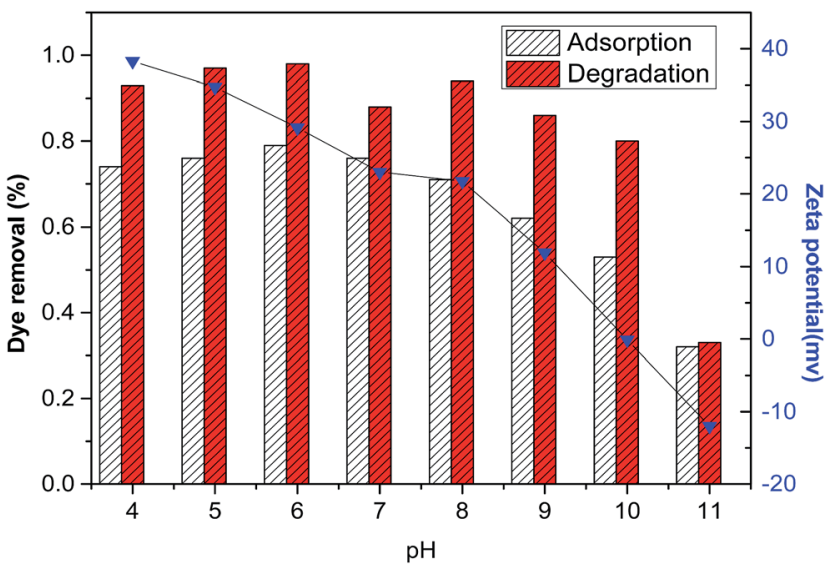

Fig. 8 Effect of initial $\mathrm{pH}$ on adsorption and dye degradation, and plots of $\mathrm{CoFe}-\mathrm{LDH}$ zeta potentials vs. solution $\mathrm{pH}$ (reaction conditions: temperature, $25^{\circ} \mathrm{C}_{;} \mathrm{H}_{2} \mathrm{O}_{2}$ concentration, $6.5 \mathrm{mM}$; catalyst loading, $0.5 \mathrm{~g} \mathrm{~L}^{-1}$; initial dye concentration, $0.02 \mathrm{~g} \mathrm{~L}^{-1}$ ).

\subsection{Mechanism of adsorption and catalytic oxidations}

Based on the above results, a possible mechanism for DR23 adsorption on CoFe-LDHs was proposed. There were three main interaction forces between DR23 and CoFe-LDHs. The first was the electrostatic attraction between the anionic sulfate groups and positively charged CoFe-LDH surface. The second was hydrogen bonds between the sulfate groups and hydroxyl groups on the CoFe-LDH surface. Furthermore, ion exchange process between the interlayer anions of LDHs and anionic groups of dyes might exist. Fig. 8 shows that there was an obvious change in DR23 removal by CoFe-LDHs with changing $\mathrm{pH}$. This indicated that electrostatic interaction between the DR23 and CoFe-LDHs was predominant.

The main processes involved in the catalytic activation of $\mathrm{H}_{2} \mathrm{O}_{2}$ by CoFe-LDHs were proposed as follows. The activation mechanism of $\mathrm{H}_{2} \mathrm{O}_{2}$ by cobalt ions was attributed to the redox pairs $\equiv \mathrm{Co}^{2+} / \equiv \mathrm{Co}^{3+} \cdot 36,37$

$$
\begin{gathered}
\equiv \mathrm{Co}^{2+}+\mathrm{H}_{2} \mathrm{O}_{2} \rightarrow \equiv \mathrm{Co}^{3+}+\cdot \mathrm{OH}+\mathrm{OH}^{-} \\
\mathrm{H}_{2} \mathrm{O}_{2}+\mathrm{OH}^{-} \rightarrow \mathrm{OOH}^{-}+\mathrm{H}_{2} \mathrm{O} \\
\equiv \mathrm{Co}^{3+}+\mathrm{OOH}^{-} \rightarrow \equiv \mathrm{Co}^{2+} \cdot \mathrm{OOH} \\
\equiv \mathrm{Co}^{2+\cdot} \mathrm{OOH} \rightarrow \equiv \mathrm{Co}^{2+}+\cdot \mathrm{O}_{2} \mathrm{H}
\end{gathered}
$$

where $\equiv$ represents surface species. As previously mentioned, the CoFe-LDH catalyst showed superior catalytic performance at $\mathrm{pH}$ values in the range $4-10$ (Fig. 8). Similar results have been reported previously. ${ }^{33}$ The mechanism above further explained that increasing the initial $\mathrm{pH}$ values facilitated $\mathrm{H}_{2} \mathrm{O}_{2}$ activation, generating a larger number of $\mathrm{OOH}^{-}$, which accelerated the reduction of $\mathrm{Co}^{3+}$ (eqn (7)-(9)). However, a further increase in the initial $\mathrm{pH}(>10)$ led to $\mathrm{H}_{2} \mathrm{O}_{2}$ decomposition into water and oxygen. This was consistent with the results shown in Fig. 8.
Table 4 Intermediate compounds identified by GC/MS

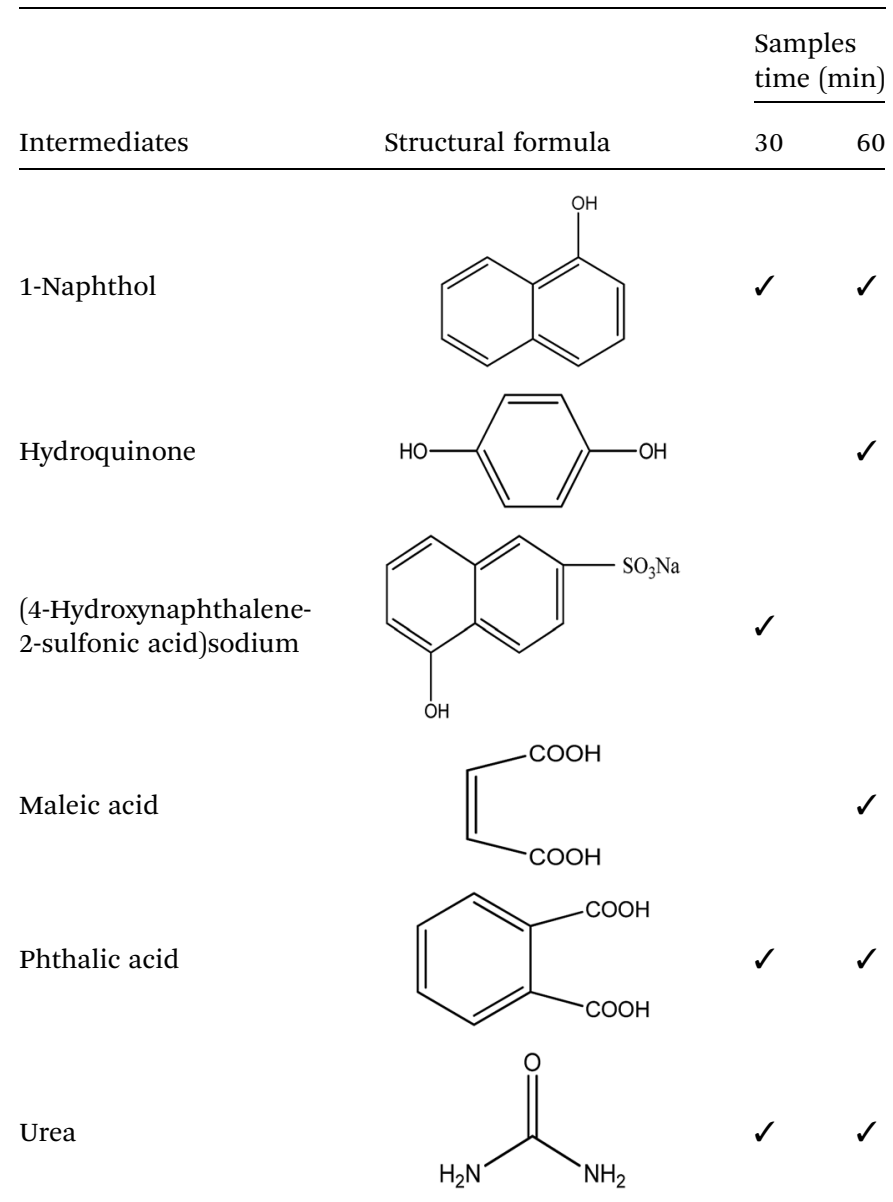

In the CoFe-LDH catalysts, iron ions played an important role in dye degradation. The mechanism of the $\mathrm{Fe}^{3+}$-initiated Fenton reaction can be described by the following reactions: $:^{38,39}$

$$
\begin{aligned}
& \equiv \mathrm{Fe}^{3+}+\mathrm{H}_{2} \mathrm{O}_{2} \rightarrow \equiv \mathrm{Fe}^{2+}+\mathrm{HO}_{2}^{\cdot}+\mathrm{H}^{+} \\
& \equiv \mathrm{Fe}^{3+}+\mathrm{HO}_{2} \cdot \rightarrow \equiv \mathrm{Fe}^{2+}+\mathrm{H}^{+}+\mathrm{O}_{2}^{\cdot-} \\
& \equiv \mathrm{Fe}^{2+}+\mathrm{H}_{2} \mathrm{O}_{2} \rightarrow \equiv \mathrm{Fe}^{3+}+\cdot \mathrm{OH}+\mathrm{OH}^{-}
\end{aligned}
$$

It should be noted that iron ions facilitate the reduction of $\equiv \mathrm{Co}^{3+}$. Considering the standard reduction potentials of $\mathrm{Co}^{2+} /$ $\mathrm{Co}^{3+}$, the reduction of $\mathrm{Co}^{3+}$ by $\mathrm{Fe}^{2+}$ was thermodynamically favorable (eqn (13)), ${ }^{39}$ meaning that $\equiv \mathrm{Co}^{2+} / \equiv \mathrm{Co}^{3+}$ and $\equiv \mathrm{Fe}^{2+} /$ $\equiv \mathrm{Fe}^{3+}$ were redox couples, as also evidenced by XPS (Fig. 2). The efficient regeneration of $\mathrm{Co}^{2+}$ at the catalyst surface would also be responsible for the superior catalytic activity of the CoFeLDHs.

$$
\mathrm{Co}^{3+}+\mathrm{Fe}^{2+} \rightarrow \mathrm{Fe}^{3+}+\mathrm{Co}^{2+}
$$

Organic intermediates generated during the Fenton reaction were detected by the GC/MS, as shown in Table 4. Based on the determined intermediates, a possible degradation reaction mechanism was speculated, as shown in Fig. 9. C-N bond 


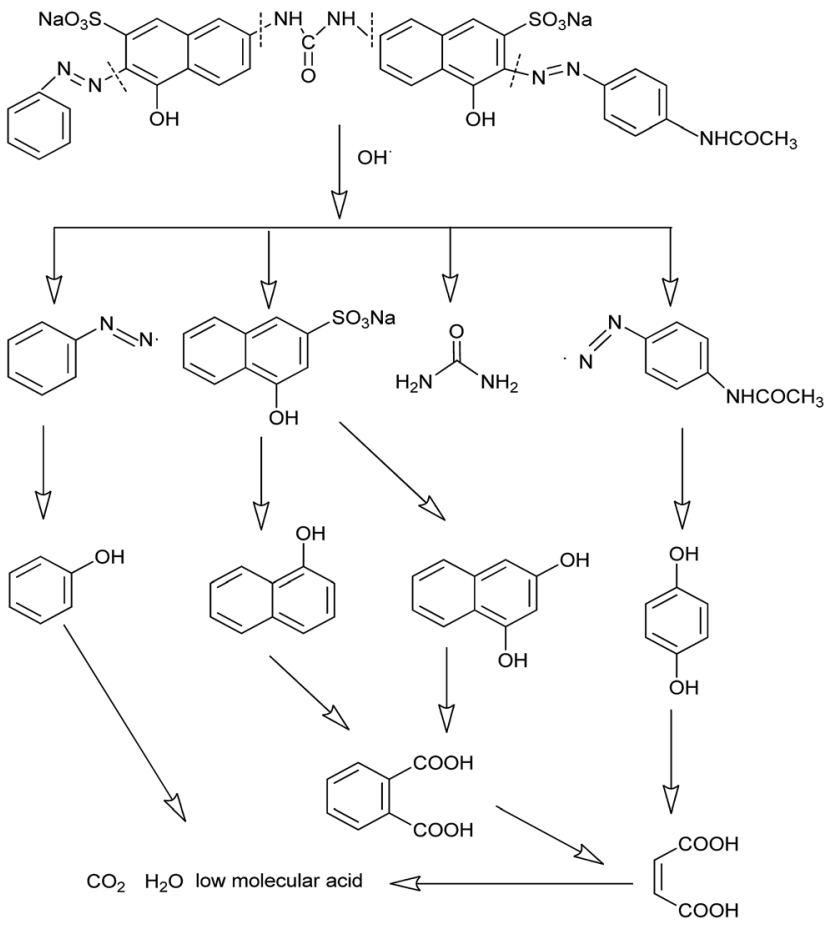

Fig. 9 Proposed mechanism for DR23 degradation on CoFe-LDHs.

cleavage was the first step of DR23 degradation, forming species including 1-naphthol, phthalic acid, urea, and hydroquinone. These intermediates were then further cleaved to form maleic acid and, finally, carboxylic acids, $\mathrm{H}_{2} \mathrm{O}$, and $\mathrm{CO}_{2}$. The degradation products obtained in this work were consistent with those reported in the literature. ${ }^{40}$

\subsection{Catalyst reusability and stability}

The recyclability of the CoFe-LDH catalyst was assessed during three consecutive cycles. As shown in Fig. 10, the degradation

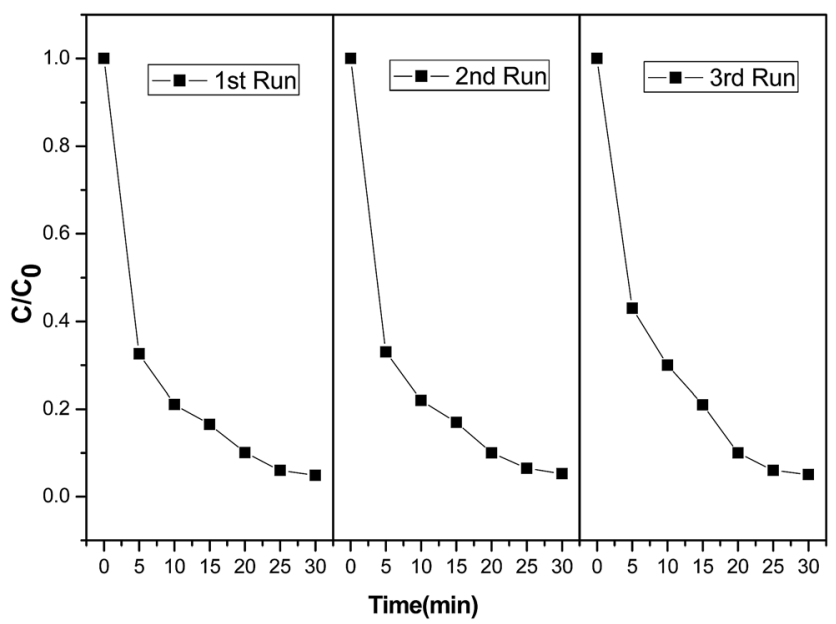

Fig. 10 DR23 degradation efficiencies of recycled CoFe-LDHs (reaction conditions: temperature, $25{ }^{\circ} \mathrm{C} ; \mathrm{H}_{2} \mathrm{O}_{2}$ concentration, $6.5 \mathrm{mM}$; catalyst loading, $0.5 \mathrm{~g} \mathrm{~L}^{-1}$; initial dye concentration, $0.02 \mathrm{~g}$ $\left.L^{-1}\right)$. efficiency of DR23 remained almost unchanged, indicating good catalyst stability and reusability. Moreover, the excellent chemical stability of the CoFe-LDH was further confirmed by XRD, FTIR, and BET (Fig. 1). No considerable change was observed after the Fenton reaction, further demonstrating the catalyst durability. The concentration of leached cobalt in the solution was less than $1 \mathrm{mg} \mathrm{L^{-1 }}$ at natural $\mathrm{pH}$ after reaction for $30 \mathrm{~min}$, which was lower than the permissible limit imposed by the Chinese government. No iron leaching was detected. The results indicated CoFe-LDH could behave as a stable and efficient heterogeneous catalyst for the removal of DR23.

\section{Conclusions}

CoFe-LDH was synthesized and tested as an adsorbent and heterogeneous catalyst for the removal of DR23 from aqueous solution. The degradation and adsorption of DR23 were studied in aqueous solutions, and the effects of initial solution $\mathrm{pH}$ on the adsorption and degradation characteristics of DR23 on CoFe-LDH were investigated. The adsorption capacity decreased with increasing solution $\mathrm{pH}$, but the variation in DR23 degradation with changing $\mathrm{pH}$ was relatively small. The experimental results showed that CoFe-LDH can be used to degrade DR23 over a wide $\mathrm{pH}$ range. XPS studies of the catalysts showed that $\equiv \mathrm{Co}^{2+} / \equiv \mathrm{Co}^{3+}$ and $\equiv \mathrm{Fe}^{2+} / \equiv \mathrm{Fe}^{3+}$ were the active catalyst species. Redox cycling during the Fenton reaction was identified and reaction mechanisms on CoFe-LDH were proposed. The metal leaching of CoFe-LDH was quite limited. These findings suggested that $\mathrm{CoFe}-\mathrm{LDH}$ was a promising catalyst for dye adsorption and degradation in aqueous solution.

\section{Conflicts of interest}

There are no conflicts to declare.

\section{Acknowledgements}

This work was supported by the Natural Science Foundation of Hubei Province, China (Grant No. 2016CFB577) and Educational Commission of Hubei Province of China (Grant No. 20171601).

\section{References}

1 T. A. Nguyen and R. S. Juang, Chem. Eng. J., 2013, 219, 109117.

2 Q. C. Ge, P. Wang, C. F. Wan and T. S. Chung, Environ. Sci. Technol., 2012, 46, 6236-6243.

3 L. Yao, L. Z. Zhang, R. Wang, S. R. Chou and Z. L. Dong, J. Hazard. Mater., 2016, 301, 462-470.

4 V. Rizzi, F. D'Agostino, P. Fini, P. Semeraro and P. Cosma, Dyes Pigm., 2017, 140, 480-490.

5 L. Bilinska, M. Gmurek and S. Ledakowicz, Chem. Eng. J., 2016, 306, 550-559.

6 E. G. Garrido-Ramirez, B. K. G. Theng and M. L. Mora, Appl. Clay Sci., 2010, 47, 182-192. 
7 M. R. Carrasco-Diaz, E. Castillejos-Lopez, A. Cerpa-Naranjo and M. L. Rojas-Cervantes, Chem. Eng. J., 2016, 304, 408-418.

8 J. Y. Feng, X. J. Hu and P. L. Yue, Environ. Sci. Technol., 2004, 38, 269-275.

9 P. V. Nidheesh, RSC Adv., 2015, 5, 40552-40577.

10 X. X. Li, Z. D. Xiong, X. C. Ruan, D. S. Xia, Q. F. Zeng and A. H. Xu, Appl. Catal., A, 2012, 411-412, 24-30.

11 P. Koilraj and S. Kannan, Chem. Eng. J., 2013, 234, 406-415.

12 L. J. Ma, Q. Wang, S. M. Islam, Y. C. Liu, S. L. Ma and M. G. Kanatzidis, J. Am. Chem. Soc., 2016, 138, 2858-2866.

13 A. R. Auxilio, P. C. Andrews, P. C. Junk and L. Spiccia, Dyes Pigm., 2009, 81, 103-112.

14 J. F. Bai, Y. Liu, X. H. Yin, H. T. Duan and J. H. Ma, Appl. Surf. Sci., 2017, 416, 45-50.

15 X. X. Tang and Y. Liu, Dyes Pigment, 2016, 134, 397-408.

16 H. T. Lu, Z. l. Zhu, H. Zhang, J. Y. Zhu, Y. L. Qiu, L. Y. Zhu and S. Kuppers, ACS Appl. Mater. Interfaces, 2016, 8, 2534325352.

17 R. Extremera, I. Pavlovic, M. R. Perez and C. Barriga, Chem. Eng. J., 2012, 213, 392-400.

18 X. X. Tang, Y. Liu and S. H. Li, RSC Adv., 2016, 6, 8050180510.

19 A. Jawad, Y. B. Li, X. Y. Lu, Z. Q. Chen, W. D. Liu and G. C. Yin, J. Hazard. Mater., 2015, 289, 165-173.

20 H. S. Zhang, J. Wang, B. Zhang, Q. Liu, S. N. Li, H. J. Yan and L. H. Liu, Colloids Surf., A, 2014, 444, 129-137.

21 N. B. H. Abdelkader, A. Bentouami, Z. Derriche, N. Bettahar and L. C. de Menorval, Chem. Eng. J., 2011, 169, 231-238.

22 Priyanka and V. C. Srivastava, Ind. Eng. Chem. Res., 2013, 52, 17790-17799.

23 S. J. Xia, F. X. Liu, Z. M. Ni, W. Shi, J. L. Xue and P. P. Qian, Appl. Catal., B, 2014, 144, 570-579.

24 K. Y. Ma, J. P. Cheng, J. Zhang, M. Li, F. Liu and X. B. Zhang, Electrochim. Acta, 2016, 198, 231-240.
25 R. Z. Ma, J. B. Liang, K. Takada and T. Sasaki, J. Am. Chem. Soc., 2011, 133, 613-620.

26 X. N. Li, J. Y. Liu, A. I. Rykov, H. X. Han, C. Z. Jin, X. Liu and J. H. Wang, Appl. Catal., B, 2015, 179, 196-205.

27 Y. P. Zhu, T. Z. Ren and Z. Y. Yuan, $R S C A d v ., 2015,5$, 76287636.

28 H. Hassan and B. H. Hameed, Chem. Eng. J., 2011, 171, 912918.

29 L. W. Chen, J. Ma, X. C. Li, J. Zhang, J. Y. Fang, Y. H. Guan and P. C. Xie, Environ. Sci. Technol., 2011, 45, 3925-3930.

30 X. J. Yang, X. M. Xu, J. Xu and Y. F. Han, J. Am. Chem. Soc., 2013, 135, 16058-16061.

31 Z. Jia, W. C. Zhang, W. M. Wang, D. Habibi and L. C. Zhang, Appl. Catal., B, 2016, 192, 46-56.

32 L. Singh, P. Rekha and S. Chand, Sep. Purif. Technol., 2016, 170, 321-336.

33 J. S. Mu, L. Zhang, M. Zhao and Y. Wang, J. Mol. Catal. A: Chem., 2013, 378, 30-37.

34 M. d. Arco, R. Trujillano and V. Rives, J. Mater. Chem., 1998, 8, 761-767.

35 J. Perez-Ramirez, G. Mul, F. Kapteijn and J. A. Moulijn, J. Mater. Chem., 2001, 11, 2529-2536.

36 Y. Shen, Z. H. Zhang and K. J. Xiao, RSC Adv., 2015, 5, 9184691854.

37 W. R. P. Barros, J. R. Steter, M. R. V. Lanza and A. C. Tavares, Appl. Catal., B, 2016, 180, 434-441.

38 Y. Wang, X. H. Lin, Z. Z. Shao, D. P. Shan, G. Z. Li and A. Irini, Chem. Eng. J., 2017, 313, 938-945.

39 Y. J. Yao, Y. M. Cai, G. D. Wu, F. Y. Wei, X. Y. Li, H. Chen and S. B. Wang, J. Hazard. Mater., 2015, 296, 128-137.

40 S. Song, H. P. Ying, Z. Q. He and J. M. Chen, Chemosphere, 2007, 66, 1782-1788. 